\section{Response to: 'Let's not fool ourselves. In RA, the ACR/EULAR remission criteria are not perfect!' by Baker et al}

Baker et $a l^{1}$ raise many interesting points on the validity and use of the American College of Rheumatology/European League Against Rheumatism (ACR/EULAR) remission criteria that I would like to reflect on.

But first of all I would like to reiterate my main point, one which I think we agree on:

In all clinical trials where remission is one of the outcomes, it should be defined according to the ACR/EULAR criteria.

Baker et al list several concerns on these criteria that are well taken, and some that are generic to the way we measure disease activity today.

Indeed, the ACR/EULAR criteria were developed with the express aim to define remission, more specifically 'to develop a definition of remission that is stringent but achievable and could be applied uniformly as an outcome measure in clinical trials'. Although the committee was asked 'to look toward, and make possible a similar definition for use in clinical practice' and in fact presented proposals to this end, the focus was on a definition for use in clinical trials. ${ }^{2}$

Likewise, and contrary to what Baker et al claim, the disease activity score (DAS) and DAS in 28 joints (DAS28) were not developed '.. . with the primary intention of measuring disease activity for the purposes of treatment escalation...'; instead, DAS and DAS28 were developed as composite instruments (indices) of disease activity for use in clinical trials. It is true that in their development, the external criterion for high disease activity was the status of a Dutch clinic patient seen around 1985 in whom therapy was switched for lack of efficacy. ${ }^{3}$

Many of the problems listed in Baker et al's letter are due to the unfortunately widespread, but nevertheless inappropriate use of these indices and definitions to guide clinical practice decisions. This includes the use of 28 joint counts that exclude the feet (OK for trials, but inappropriate in patient care) and the patient global visual analogue scale (VAS) threshold of 1 out of 10 (clearly unachievable for many patients seen in the clinic). The choices made for the ACR/EULAR criteria reflect compromises at several levels to obtain, in the end, a set that performs optimally in the trial setting.

As already noted in the paper publishing the criteria, imaging was purposefully excluded, mainly for reasons of feasibility. Although singly the elements of the criteria can still be compatible with residual disease activity (eg, one swollen and one tender joint), together they result in an optimally specific set, with very limited numbers of 'false positives'. Nevertheless, as Baker et al point out, the criteria can still both 'underdiagnose' (as in the case of a VAS >1) and 'overdiagnose' remission (as in the case of a patient with residual disease on imaging). The prognostic relevance of such 'errors' is not clear but likely small on the group level. Another known limitation my group is currently working on is the relative lack of patient-reported input into the criteria. ${ }^{4-6}$ Finally, Baker et al find fault with the criteria for not performing better than DAS2 $8<2.6$ in the prediction of which patients will flare after treatment discontinuation.
I do not think this is a fair argument, because the criteria were never developed with this purpose in mind; also, the argument is built on the unproven assumption that on tapering treatment, patients in remission are less likely to flare than patients in a minimum disease activity state.

In conclusion, I feel the ACR/EULAR criteria are a 'fait accompli' but not forever! They should be put up for revision once sufficient experience in trials has been gained. It may very well be that at that time feasible biomarkers are available to improve their performance or that robust evidence (currently lacking) suggest the thresholds should be altered. In the meantime, they are for the seasoned clinician to 'use wisely', as they were not meant for, let alone optimised for application in clinical practice. There is an urgent need for a disease activity tool that is valid and reliable for use in individual patient care, especially in the range between low disease activity and absence of disease.

\section{Maarten Boers}

Department of Epidemiology and Biostatistics; Amsterdam Rheumatology and Immunology Center, VU University Medical Center, Amsterdam, The Netherlands

Correspondence to Dr Maarten Boers, Department of Epidemiology and Biostatistics, Amsterdam Rheumatology and Immunology Center, VU University Medical Center, PO Box 7057, Amsterdam 1007 MB, The Netherlands; eb@vumc.nl

\section{Competing interests None.}

Provenance and peer review Commissioned; internally peer reviewed.



To cite Boers M. Ann Rheum Dis 2017:76:e13.

Accepted 10 November 2016

Published Online First 1 December 2016

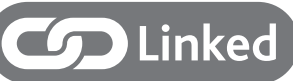

http://dx.doi.org/10.1136/annrheumdis-2016-210797

Ann Rheum Dis 2016;76:e13. doi:10.1136/annrheumdis-2016-210799

\section{REFERENCES}

1 Baker KF, Pratt AG, Thompson B, et al. Let's not fool ourselves. In RA, the ACR/ EULAR remission criteria are not perfect! Ann Rheum Dis 2017;76:e12.

2 Felson DT, Smolen JS, Wells G, et al. American College of Rheumatology/European League against Rheumatism provisional definition of remission in rheumatoid arthritis for clinical trials. Ann Rheum Dis 2011;70:404-13.

3 van der Heijde DM, van 't Hof MA, van Riel PL, et al. Judging disease activity in clinical practice in rheumatoid arthritis: first step in the development of a disease activity score. Ann Rheum Dis 1990;49:916-20.

4 van Tuyl LH, Sadlonova M, Davis B, et al. Remission in rheumatoid arthritis: working toward incorporation of the patient perspective at OMERACT 12. J Rheumatol 2016:43:203-7.

5 van Tuyl LH, Hewlett $S$, Sadlonova $M$, et al. The patient perspective on remission in rheumatoid arthritis: 'You've got limits, but you're back to being you again'. Ann Rheum Dis 2015;74:1004-10.

6 van Tuyl LH, Sadlonova M, Hewlett $\mathrm{S}$, et al. The patient perspective on absence of disease activity in rheumatoid arthritis: a survey to identify key domains of patient perceived remission. Ann Rheum Dis doi: 10.1136/annrheumdis-2016-209835 